\title{
VITAMIN A DEFICIENCY IN NIGERIAN CHILDREN
}

\author{
AJAIYEOBA A. I. \\ Department of Ophthalmology, University College Hospital, Ibadan, NIGERIA.
}

Vitamin A deficiency (VAD) is a global problem of public health significance in many under-privileged communities of the world. No national data is available on the vitamin A status in Nigeria. A population-based, cross-sectional study, using a two-staged stratified cluster sampling method was conducted. The national prevalence of Xerophthalmia was $1.1 \%$ whilst the national prevalence of VAD using serum retinol < 20 $\mathrm{g} / \mathrm{dl}$ (or $0.7 \mu \mathrm{mol} / \mathrm{l}$ ) as cut-off was $28.1 \%$; both values are indicative of a problem of public health significance. This paper evaluates the implications of vitamin A deficiency in Nigeria. There is an urgent need for the relevant authorities to pursue active and realistic policies in order to prevent further unnecessary blindness, morbidity and mortality in Nigerian children.

Keywords: Vitamin A deficiency, Nigeria, Children

\section{INTRODUCTION}

Vitamin A deficiency (VAD) is a global problem of public health significance in under- privileged communities of the world (World Health Organisation, 1995). There is a high prevalence of VAD in Asia, Latin America and Africa (World Health Organisation,1994). Very little data is available about Vitamin A status in Nigeria. Reports (Oomen, 1977; Adeyefa, 1991) on this subject were not only old and scanty, but dealt with specific aspects of Vitamin A deficiency which focused on particular population and in different geographical locations in Nigeria. The clinical eye signs of VAD or xerophthalmia have been defined by WHO (World Health Organisation, 1982). Xerophthalmia is the most readily recognized and the most widely employed criterion(World Health Organisation, 1982) for discussing whether VAD poses a significant public health problem in any particular community. Xerophthalmia includes all ocular manifestations of VAD, from night blindness (NB) to corneal scarring and resultant blindness. In 1982, the list of countries where VAD had assumed public health $(\mathrm{PH})$ significance, based on clinical eye signs (xerophthalmia) were enumerated by $\mathrm{WHO}$ (World Health Organisation,1994). No data was available about the status of Nigeria and was therefore categorized as such.

It has also been established (Sommer et al, 1983) that VAD increases the risk of childhood morbidity and mortality. Complications of conditions like malnutrition, measles and diarrhea commonly associated with VAD rank amongst the leading causes of morbidity in Nigerian children (Nigerian Demographic Survey, 1992). It is therefore important to know Vitamin A status of Nigerian children and relate it to the high prevalence of blindness (Olurin,1974; Sandford-Smith, 1979; Ajaiyeoba, 1994; Ezepue, 1995) morbidity and mortality. It has been documented (Sommer et al, 1986) that there is reduction in morbidity and mortality in VAD related illness when the diet is supplemented with Vitamin A. This practice been established as one of the most cost effective (Beaton et al, 1993) phenomenon in medical practice.

\section{MATERIALS AND METHODS}

The survey was a population-based, crosssectional study, part of a national survey conducted in
Nigeria between June and September 1993, designed to estimate the prevalence of VAD and xerophthalmia in the four health zones of Nigeria. Respondents were selected, using a two-stage stratified cluster sampling method. The health zones have been designated by the Federal Ministry of Health for ease of administration and service delivery of the Primary Health Care programme in Nigeria. The health zones also mirror the geographic and ethnic distribution, and are of comparable population sizes. These health zones are- Southeast (SE), Southwest (SW), Northeast (NE) and Northwest. (NW)

For population census purposes the country is divided into enumeration areas. An enumeration area (EA) is defined as an area, within which 500 households could be found. The national master sample for the National Integrated Survey of Households (NISH) programme was used as the basis of sampling frame for the study. The sampling frame comprised of $2520 \mathrm{NISH}$ enumeration areas (i.e. $2520 \times 500=1,260,000$ households). These were made up of 600 EAs in each of the NW, NE and SW zones and 720 EAs in the SE zone.

A base population of 720 (the largest NISH EA in a zone) was used. This gave a required sample size of $21 \mathrm{EAs}$ i.e. clusters per each health zone. To correct for the potential effect of clustering in the level of subclinical deficiency of Vitamin A, a design effect of 2, as suggested by the World Health Organisation for population-based surveys in developing countries was applied. This was also the effect computed and used for the National Demographic and Health Survey (Nigerian Demographic Survey, 1992). Therefore, the required number of clusters per health zone was $21 \times 2=$ 42 EAs.

However, in nutritional surveys, cluster samples larger than 30 clusters do not appreciably improve precision. Therefore, in each health zone a sample size of 30 EAs ( clusters) were selected with a total of $120 \mathrm{EAs}$, nationally. Sampling of EAs was by systematic random sampling method after stratification of all EAs by type .In each zone, a list of all EAs was obtained through the mapper from the Federal Office of Statistics .

According to the UNICEF (1990) report on the situation of women and children in Nigeria, children under the age of 4 years constituted $18 \%$ of the 
Nigerian population. It may thus be estimated that there are about 20 million children under 6 years of age, with about 100 children per EA. With $80 \%$ power and $95 \%$ precision, a sample size of about 22 children per EA were required. A correction factor of $15 \%$ for nonresponse at biological screening particularly blood collection was incorporated in the calculation. This gave a required sample size of 32 children per EA, giving a national sample of 4200 children and their mothers .

Screening and examination were done by ophthalmologists in most areas. However, in areas where ophthalmologists were not available, ophthalmic residents and nurses did the screening. Both ophthalmic residents and nurses were trained to apply a standardised examination procedure. The screening/examination procedure followed WHO criteria and staging (Wittpenn et al, 1988) of xerophthalmia for field examination. Ophthalmic examination was carried out with the aid of a pen torch and use of magnification (e.g. loupe). All children's eyes were stained with flourescein dye in order to assess subtle corneal changes, which may be indicative of xerophthalmia. Presence /absence of other clinical features associated with xerophthalmia were also inquired about and noted. Blood samples obtained from all children were assessed for retinol using reversed phase, high pressure liquid chromatography (HPLC) method (Catignani and Bieri, 1983)

Ethical approval for the study was obtained from the Joint Ethical Committee of the College of Medicine, University of Ibadan and the University College Hospital Ibadan, Nigeria. Informed consents were obtained from mothers or guardians after carefully explaining all procedures.

\section{RESULTS}

A total of 2905 children between 6 and 71 months of age were screened for xerophthalmia and VAD. However, data on retinol of some children lacked details or vital information required for meaningful analysis in some aspects of the study. These were largely due to refusal of blood collection, inadequate/undesirable samples (haemolysed), labeling errors, or improper/none entry of vital data. These records were therefore excluded in order to improve the quality of the results. Therefore only the retinol results of 1244 children were reliable for meaningful evaluation.

The national prevalence of Xerophthalmia was $1.1 \%$. The prevalence of Xerophthalmia in each health zone is shown in Table 1. The highest prevalences were recorded in the south- west and north west zones. No single case of Xerophthalmia was recorded in the southeast zone. The age distribution and prevalence of Xerophthalmia are shown in Table 2. The highest prevalence was observed in children aged between 60 and 71 months. The national prevalence of nightblindness was $1 \%$. Table 3 shows the prevalence of children with VAD ( retinol $<10 \mathrm{ug} / \mathrm{dl}$ ) presenting with different stages of Xerophthalmia. Corneal xerosis (stage X2) was the commonest ocular presentation amongst Vitamin A deficient children. The prevalence of nightblindness amongst children with 2 week history of diarrhoea was $1.5 \%$, whilst that amongst those without diarrhoea was $1 \%$. No child with antecedent (3 months) history of measles infection presented with nightblindness.

Table 1: The prevalence of xerophthalmia by health zones

\begin{tabular}{lcccc}
\hline & $\begin{array}{l}\text { No. } \\
\text { screened }\end{array}$ & $\begin{array}{l}\text { Xerophth } \\
\text { cases }\end{array}$ & $\begin{array}{l}\% \\
\text { Xerophth } \\
\text { in zones }\end{array}$ & $\begin{array}{l}\text { \% } \\
\text { No. Total } \\
\text { Xerophth }\end{array}$ \\
\hline Southeast & 717 & 0 & 0 & 0.0 \\
Southwest & 776 & 17 & 2.2 & 51.5 \\
Northwest & 816 & 4 & 0.5 & 12.1 \\
Northeast & 596 & 12 & 2.0 & 36.4 \\
\hline National & 2905 & 33 & & 100.0 \\
\hline
\end{tabular}

Table 2 : Age Distribution and prevalence of Xerophthalmia in Nigerian children.

\begin{tabular}{|c|c|c|c|}
\hline $\begin{array}{l}\text { Age group } \\
\text { (months) }\end{array}$ & $\begin{array}{l}\text { Total No. } \\
\text { Screened }\end{array}$ & $\begin{array}{l}\text { Xerophth } \\
\text { cases }\end{array}$ & $\begin{array}{l}\text { Prevalence } \\
(\%)\end{array}$ \\
\hline $6-11$ & 269 & 2 & 0.74 \\
$12-17$ & 326 & 2 & 0.61 \\
$18-23$ & 282 & 3 & 1.06 \\
$24-35$ & 566 & 9 & 1.54 \\
$36-47$ & 499 & 3 & 1.40 \\
$48-59$ & 376 & 7 & 0.80 \\
$60-71$ & 330 & 33 & 2.12 \\
\hline & 2648 & & \\
\hline
\end{tabular}

Table 3: Prevalence of children with vitamin A deficiency and stages of Xerophthalmia.

\begin{tabular}{|c|c|c|c|}
\hline $\begin{array}{l}\text { Stages of } \\
\text { xerophthalmia }\end{array}$ & $\begin{array}{l}\text { No of children } \\
\text { with } \\
\text { Retinol level } \\
<10 \text { ug/dl } \\
\text { (deficient) } \\
\end{array}$ & $\begin{array}{l}\text { No of children } \\
\text { with } \\
\text { Retinol level } \\
>10 \mathrm{ug} / \mathrm{dl}\end{array}$ & Total \\
\hline No Xerophth & 98 & 1130 & 1228 \\
\hline XIA & 0 & 0 & 0 \\
\hline XIB Bitot spot & 1 & 1 & 2 \\
\hline $\begin{array}{l}\text { X2 Corneal } \\
\text { xerosis }\end{array}$ & 1 & 12 & 13 \\
\hline $\begin{array}{l}\text { X3A/B } \\
\text { Corneal ulcer }\end{array}$ & 0 & 0 & 0 \\
\hline $\begin{array}{l}\text { XS Corneal } \\
\text { scars }\end{array}$ & 1 & 0 & 1 \\
\hline Total & 101 & 1143 & 1244 \\
\hline
\end{tabular}


The national prevalence of marginal vitamin $A$ deficiency (defined by serum retinol $<20 \mu \mathrm{g} / \mathrm{dl}$ or 0.7 $\mu \mathrm{mol} / \mathrm{l})$ was $28.1 \% \quad(95 \%$ confidence interval $25.4-$ $31.0 \%)$ and severe retinol deficiency $(10 \mu \mathrm{g} / \mathrm{dl}$ or 0.35 $\mu \mathrm{mol} / \mathrm{l}$ ) was $7.0 \%$ (95\% confidence interval $5.5-8.8 \%$ ). The distribution curve was positively skewed and differed significantly from the normal (Gaussian) pattern. The values ranged from 5 to $134 \mathrm{ug} / \mathrm{dl}$. The national mean serum retinol value was $31.8 \mathrm{ug} / \mathrm{dl} .(\mathrm{SD}=18.6)$.. The highest prevalence for VAD using serum retinol, were found in the northeast and northwest zones with rates of $49.6 \%$ and $48.6 \%$ respectively. The prevalence of vitamin A deficiency, using serum retinol as an indicator, showed no sex difference. Prevalence peaked at age 24-47 months. Low serum retinol was associated with a history of diarrhoea in the previous two weeks. Children who had diarrhoea in the preceding two weeks, had about twice the risk of low serum retinol than those who had no diarrhoea.

\section{DISCUSSION}

From the result of this study, a national prevalence of Xerophthalmia of $1.1 \%$ and VAD of $7 \%$ and are both indicative of a problem of public health significance. The main findings of this study were the high prevalence of Xerophthalmia in both the southwest and northeast zones and VAD in northwest and northeast zones. Within the limits of the population of respondents studied, it can be implied that many children in some communities in the northeast, northwest and southwest zones were particularly at risk of VAD and its consequences.

Children between the ages of 60-71 months were particularly vulnerable to VAD. This may not be surprising, because by this time the Vitamin A store, which was enriched through breastfeeding during infancy and weaning period, would have been exhausted. Using serum retinol as indicator, highest prevalence of vitamin A deficiency was found in the North East, 49.6\%, and North West Zones (48.6\%). In the South Eastern Zone, the prevalence of vitamin $A$ deficiency was lowest. This observation is in agreement with other authors (Oomen, 1977) who attributed it to the fact that in the southern savannah zone, oil palm is cultivated and consumed regularly. In this study, it was observed that most of the sauces, potages and soups consumed in the southern Zones were prepared using palm oil; a practice more common in the South East than in other Zones. Oomen attributed VAD in northern Nigeria to common use of vegetable rather than red palm oil for cooking, whereas red palm oil is freely used in the southwest. Whereas red palm oil contains high concentration of vitamin $A$, vegetable oil contains relatively less. The problem, however in the southwest could be due to the style of cooking in these communities, where red palm oil is usually boiled/ bleached before employed for cooking, by which time all the Vitamin A content would have been destroyed.

Night blindness was prevalent in Nigerian children despite the difficulties in eliciting such history. This may be due to the fact that local terminologies already exist in many Nigerian communities, and further confirms that VAD is not a new phenomenon in most communities in Nigeria. The significance of night blindness as a screening tool for VAD in Nigeria is the subject of another study (Ajaiyeoba et al, 1996)

It is notable that stage X2A (corneal xerosis), was the commonest presentation amongst children with Xerophthalmia. However dryness of the cornea may be due to environmental/climatic factors, or to other conjunctival diseases e.g. trachoma and vernal conjunctivitis that are known (Sandford-Smith, 1986) to be prevalent in Nigerian communities. Very surprising however, is that no single case of stage 3 (corneal ulceration) was found in this study. It may be that, since this represents a rather advanced stage (Sommer, 1982) of VAD, many of these children would most likely have developed other complications and succumbed because of the attendant high mortality.

An interesting finding in this study, however was that many children with night blindness also had diarrhoea. However, a statistically significant correlation could not be established between these two parameters. Meanwhile, it has been documented (Stoll et al,1995) that most children with persistent diarrhoea may be VA deficient. In this study, only $1.5 \%$ of children with diarrhoea had night blindness. Notwithstanding diarrhoeal diseases are very rampant in Nigerian children because of poor environmental sanitation, and are closely associated with nutritional deficiencies. Malnutrition is not due to poverty as much as ignorance of what to eat, in order to meet the requirements of good VA nutriture.

Also in this study there was no obvious relationship between night blindness and measles infection. Measles, like other diarrheal diseases is very common (Nigerian Demographic Survey, 1992) in Nigerian children and expectedly renders the child vitamin $A$ deficient. This may explain the reason why measles infection has rather grave consequences on Nigerian children, apart from being the commonest cause of blindness (Olurin,1974; Sandford-Smith, 1979; Ajaiyeoba 1994; Ezepue, 1995)s in Nigerian children despite purported successful implementation of the Expanded Programme on Immunisation (EPI). Many reasons may account for why night blindness was not associated with measles infection. Firstly, history of night blindness may be difficult to elicit partly because of difficulties in interpretation especially in those communities where no local terminology is available. More importantly is the social stigma attached to such deficiency in African communities. Hence many parents will readily deny history of night blindness.

Also night blindness takes some time to develop and children with this condition may withdraw from their peer, thereby concealing this deficiency. The attendant high mortality in measles/and VAD may not make it possible to come across many children with measles, let alone elicit any history of night blindness.

By projection of the results of this study, this means that about one million children are affected, out of which approximately 100,000 may suffer eye involvement and 50,000 may go blind and approximately 25,000 children may die every year from VAD (Sommer, 1995). There is a dangerous vicious cycle between VAD, diarrhea on one hand, measles infection (Forster and Yorston, 1992) and malnutrition (McLaren, 1991) on the other, whereby each of these compliment one another to make 
the situation critical (Sommer, 1995). for the child, that may go blind (Forster and Sommer, 1987)if he survives. This horrific picture demonstrates the outlook of VAD in our communities today.

This cycle needs to be broken in order to reverse the child back to a state of good health, which centers around good nutrition with adequate vitamin $A$ intake, measles vaccination and a clean environment. In Nigeria, there are established policies and programmes in place to address these problems for almost 3 decades, with resultant little or no improvement.

The Expanded Programme of Immunisation, at the moment is not well articulated. There is a need to reevaluate this programme and specifically review the delivery, transportation, distribution, coverage and preservation of vaccines currently in use with a view to incorporate Vitamin A distribution.This step will augur well for a proper immunisation (Sommer ,1995) programme.

Vitamin A supplementation and other related programmes $(\mathrm{WHO}, 1988)$ are effective and have led to increased survival (McLaren,1991; Herrera et al,1992) in communities where such programmes are well articulated and actively pursued. As a matter of fact, it is on record as being one of the earliest and cost effective (Beaton et al1993) programmes in medical practice.

\section{Acknowledgements}

Many thanks to members of the Nigerian Micronutrients Survey (NMS), the Nigerian Federal Ministry of Health and the United States Agency for International Development (USAID).

\section{REFERENCES}

Adeyefa IO (1991). Vitamin A status and the effect of oral supplementation in pregnant Nigerian women. Ph D thesis University of Ibadan.

Ajaiyeoba Al (1994). Childhood blindness in Nigeria. Nig J Paediatr. 21(2):43 - 6.

Ajaiyeoba Al, Samaila E, Asana EU, Ezepue UF (1996). Use of Night blindness for Xerophthalmia screening in Nigeria. Nig J Ophthal.4(1):12-14.

Beaton GH, Martorelle R, Aronson KJ, et al.(1993) Effectiveness of Vitamin A Supplementation in the Control of young child mortality in developing countries. ACC/SCN State of the Arts Series, Nutrition Policy Discussion Paper.No13, Geneva.

Catignani GL, Bierri JG (1983). High Pressure Liquid Chromatography. Clin. Chem. 29:708-712.

Ezepue UF (1995). Vitamin A deficiency: a causal factor in childhood corneal diseases and blindness in eastern Nigeria. Nig J Ophthal. 2(3):35 - 9.

Foster A, Yorston D (1992). Corneal ulceration in Tangayikan children: relationship between measles and vitamin A deficiency. Trans R Soc Trop Med Hyg. 86: 454-455.
Foster A, Sommer A (1987). Corneal ulceration, measles and childhood blindness in Tanzania. Brit $\mathrm{J}$ Ophthal 71:331-343.

Herrera MG, Nestel P, El Amin (1992) Vitamin A supplementation and child survival. Lancet 340:226231.

McLaren DS (1962). Malnutrition and the eye: Academic Press. New York.172-214.

McLaren DS (1991). Vitamin A supplementation and mortality. Lancet 338: 1202-1209.

Nigerian Demographic Survey (1992). Nutritional Status of Children under Five years of Age. Federal Office of Statistics. Lagos.

Olurin O (1974). Etiology of Blindness in Nigerian Children. Am. J Ophthal 70(4):533-540.

Oomen JMV (1977). Xerophthalmia in northern Nigeria. Tr Geogr Med 23:245 - 9.

Sandford-Smith JH, Whittle HC (1979). Corneal Ulceration following measles in Nigerian children. $\mathrm{Br} \mathrm{J}$ Ophthal 63:720-4.

Sand ford - Smith J. (1986). Eye Diseases in Hot Climates. Wright. Bristol.

Sommer A, Tarwotjio I, Hussainni G, Sussanto D (1983). Increased mortality in children with Vitamin A deficiency. Lancet 2:585-588.

Sommer A, Tarwotio I, Djunaedi E et al.(1986) Impact of vitamin A supplementation on childhood mortality- A randomized controlled community trial. Lancet 1:11691173.

Sommer A. Nutritional Blindness (1982). Xerophthalmia and Keratomalacia. Oxford University Press. New York.

Sommer A (1995). Vitamin A deficiency and its consequences. WHO $3^{\text {rd }}$ edition, Geneva.

Sommer A (1995). Vitamin A and measles vaccination. Lancet 346:252.

Stoll BJ, Banu H, Kabir I, Molla A (1985) . Night blindness and Vitamin A deficiency in children attending a diarrhoeal disease hospital in Bangladesh. J. Trop. Paediatr. 31: 36-40.

Withpen JR , West KP , Keenum D (1988). ICEPO Training Manual .Assessments of vitamin A status by impression cytology. The John Hopkins University, Baltimore.

World Health Organization (1995). Global prevalence of vitamin A deficiency. WHO/NUT/95.3.Geneva.

World Health Organization (1994).Countries categorized by degree of health importance of vitamin A deficiency by WHO region. WHO Bulletin. Annexe 1.

World Health Organization (1982). Control of Vitamin A deficiency and Xerophthalmia. Technical report series no 672.Geneva.

World Health Organization (1988). Vitamin A Supplement. A guide to their use in the treatment and prevention of Vitamin A deficiency and Xerophthalmia. WHO/ UNICEF/IVACG.Geneva. 